obtained in the $C B A$ strain (a low mammary cancer strain) while all the treated mice of the Strong $A$ strain developed tumours. Other strains gave intermediate responses : the 'white label' and IFS strains gave a fow tumours, and the $R$ III strain a moderate number of testicular tumours if the mice lived long enough.

The British Empire Cancer Campaign has been concerned with research for twenty-one years and is now taking on the additional duty of advising medical practitioners as to the value of any new form of treatment about which the Campaign has knowledge.

E. BOYLAND.

\section{GENETICAL ASPECTS OF THE CANCER PROBLEM}

A "PRELIMINARY Report on a Survey of the Situation in Cancer", by Dr. Fritz Blank, appears in the Archives of Surgery, Chicago (49, No. 5, $301 ;$ 1944). The general interest of the study warrants a digest showing the limits of the field surveyed and the findings. In his foreword, Prof. F. A. E. Crew points out that this survey of the biological background in cancer is the first major attempt by the Bureau of Human Heredity (115 Gower Street, London, W.C.1) to present the results which can be achieved through the 'clearing-house method'. It has been made possible by international collaboration between the Institute and the Department of Medical Genetics of Ohio State University, both of which are foci of much friendly co-operation between individual workers and numerous institutes.

The Bureau of Human Heredity has been developing the mechanism for such work as this since it opened in 1936. The method by which the crossreference index is made is best compared to a great sorting machine. The desiderata were outlined early on by Profs. R. A. Fisher and J. B. S. Haldane in consultation. It works well ; three thousand sections on constitution and traits were already available when Dr. Blank began the cancer collection; points in the present survey can be set against a further 1,500 or so. This preliminary survey covers most of the literature between 1900 and 1941, with data from about four thousand papers.

The summarized genetical findings are not the less important for presenting no surprises. The myth of hereditary cancer is disposed of. Geneticists are more and more aware in other fields of the fact that hereditary make-up controls type of constitution; in other words, individual variations in physiological function. There is evidence from many sources that carcinogenic agents react differently on various types of constitution. This would be expected from physiological genetics. An illuminating point may be gleaned here, namely, that certain types respond quickly to diverse kinds of irradiation. In another series it appears to be mainly hormone imbalance which prepares the body for growths and/or malignancy. Fortunately, data give at least a rough guide as to means of differentiating between these two major sources of the disease.

It is significant to learn that certain diseases of hereditary type appear frequently as precursors of neoplastic growth and malignancy. Here the clearinghouse method may have special importance. Practi- tioners, by contributing their observations to the Centre, will do much to accelerate accumulation of knowledge of practical value to their colleagues and to humanity.

Dr. Blank's survey is set out in chapters dealing with those aspects in which research was sufficiently advanced in 1940 to show a bearing on the biological background; no reference is therefore made to the data on nuclear division, including polyploidy and extrachromosomal factors, on which researches are now in progress. Statistics come first : of high genetical interest are comparative figures for different parts of the world and different races. These show that for all those areas and peoples for which reliable figures are available, the general incidence of cancer is practically the same, although site and type of the disease vary greatly; and there is a hint in the Dutch East Indies that hereditable racial characteristics underlie this fact where Malays and Chinese working side by side demonstrate racial incidence comparable to that of their home areas.

Detailed studies in Norway (Waaler, 1931), later repeated by Wassink in Holland, throw light on the question in general and show the complexity of the problem. Greenwood's analysis is as follows: (1) "some forms of cancer (e.g. lip cancer) are produced quite independently of any inheritable anlagen extrinsic factors have greater, perhaps exclusive, influence upon males; (2) the heritable factors show two independent factors, both of which occur with a frequency of about 16\%". These, according to Wassink, are the existence of a general predisposition and also a tendency to certain localization.

'Cancer families' are reviewed, beginning with studies in 1856 ; it has been shown that simple statistical study here is unreliable (Cramer, 193i), since in large families where sibs survive to thirty. five years, the expectation will be approximately that of the general population. Twin studies are mentioned, but since none conforms to the criteria set up by von Verschuer and Kober, the findings are omitted from the general argument.

The work on rodents receives notice proportionate to its importance and covers spontaneous tumours and the reaction of different strains to transplantation and induced tumours. In each series sharp differences in incidence and reaction are noted between stocks within any given species or variety: there are immune, partially immune or tumour-prone. There remains an unresolved problem here in a change of average incidence in experiments with foster suckling (the so-called milk factor). But here also a variation in resistance of the stocks persists; recent work on agglutinogens in milk were not available at the date to which the survey is carried.

Carcinogenic agents are surveyed in detail; the organic type, the viruses, have been the focus of the search for a possible causative factor or prime agent. Occupational cancers stimulated research on chemical agents, and these are reviewed. Work with hormones proceeding over the same period is not unrelated to those investigations; of these, œstrin has given important results, namely, the production of mammary cancer in 100 per cent of male mice in a cancerprone stock. Cramer and Horning relate this to a heritable faulty metabolism shown as 'brown degeneration of the adrenals'.

Of great practical interest are the data on those diseases with genetic background which are frequent precursors of cancer. These are spoken of as the internal carcinogenic environment. In addition to 
nouro-fibromatosis and xeroderma pigmentosum, achlorhydria is typical. The racial data demonstrate a constitutional susceptibility to physical irritants, particularly radiation. The work of Roffo and Findlay calls for further research in this direction although the general facts are clear.

Dr. Blank concludes that the complexity of factors noted above will be found to prevail equally in most forms and types and sites of tumours. As the cases of eancer in which we can trace direct hereditary transmission are rare, admittedly they cannot provide a valid answer to the question of whether, or to what extent, an inherited susceptibility plays a part in the general incidence of malignancies. From disorders indicating a purely hereditary proneness to tumour formation, such as xeroderma pigmentosum or neuro-fibromatosis, must be differentiated many other types of tumour formation about which nothing yet is known of an inherited tendency as, for example, cancer of the lip, which according to Waaler seems to be distributed quite independently of any inherited disposition.

Much remains to be done before these problems can be solved, but our task will be lighter if we heed the lesson already taught, namely, that it is vain to ask, "Is cancer hereditary ?" and that we must inquire separately for each organ, tissue and type of the disease, whether any hereditary factors, direct or indirect, are involved in a specific form of the malady.

Summarizing our present position meanwhile, we can say that enough evidence has been accumulated to warrant at least the following statements: (a) Cancer is not a unit disease, at least so far as its genetical behaviour is concerned. Tumours of different sites and types differ in their genetical behaviour. (b) Therefore it is unlikely that a heritable condition of 'cancer' exists as such. (c) There does exist a general inherited disposition, whether of susceptibility or refractoriness to tumour formation. (d) In certain individuals factors exist, most probably inherited quite independently of a general disposition, which govern the localization of the disease. This localization in turn seems to depend upon a favourable 'intermal environment' in certain tissues or organs. (e) If general susceptibility and inherited favourable internal environment are combined in an individual, these factors may be strong enough in themselves to lead to cancer formation in certain tissues. ( $f$ ) If general susceptibility is very marked in an individual, even relatively slight irritation by agents of many kinds may lead to cancer formation. $(g)$ But quite apart from these heritable conditions, there exist purely external carcinogenic agents of various kinds, which are obviously strong enough to lead to cancer-formation in certain tissues, even in individuals in whom there is no inherited predisposition, or perhaps it is too weak to be detected by methods used at present in testing for hereditary traits.

The above is a picture of cancer research as seen by the genetically minded physician. The chief aim of the survey has been to show that the whole problem of heredity and cancer is a biological question of highly practical bearing. The writer endorses MacDowell when he says: "It is highly regrettable that outside the immediate circle of geneticists, there seems to be an impression that the gene is selfsufficient and is either dominant or recessive. Especially as applied to neoplasms, this misunderstanding has led to erroneous conclusions both on the part of hostile critics and ardent believers. Dominance is only a special case at the end of a continuous series of interrelations between pairs of genes. . . . No gene can produce its effect without the cooperation of many other genes. . . . And genes and extrinsic conditions cooperate in all cases". Anthony Feiling.

\section{POPULATION PROBLEMS IN BRITAIN}

GIR W. LANGDON-BROWN, addressing the $\curvearrowright$ British Social Hygiene Council on the relation of social biology to the population problem (Brit. Med. $J ., 766$, Dec. 9, 1944), said that he regarded with grave suspicion the efforts of planners to dethrone the family and hand children over to the State. Some family life is unsatisfactory, but the majority is good. The birth-rate in Britain has fallen steadily since 1870 and, in the same period, the infant death. rate had decreased and expectation of life had lengthened. There is evidence that the fertility-rate decreases with improved chances of survival. The British Social Hygiene Council has estimated that one-tenth of all marriages in Britain remained childless, but not deliberately so. A study of 2,000 cases suggested that in 60 per cent there was a defect on the man's part. In general, the average male fecundity is much lower than was generally assumed.

Other factors operating against the family are increased rents and rates, which absorb much more than the one tenth of income allowed for these in the Victorian scheme of things. This means that money which should go for food is spent on housing, with alarming effects on infant mortality and family life. There is an increase in life in flats due to aggrega. tion of urban populations, and flats are unsuitable for children. A standard rate of family allowances would not be satisfactory. The effects of late marriages and the consequent celibacy forced on our younger people by social changes must be recognized and studied by social biologists.

These and allied problems are the subject of $a$ booklet issued by the Tory Reform Committee entitled "Tomorrow's Children" (P. S. King and Staples, Ltd., 14 Great Smith Street, London, S.W.1, 1s. net). This pamphlet rejects the thesis that the world will get too full in the future, because efforts to raise the birth-rate cannot do more than arrest the decline and because the progress of invention and science is always enabling us to support far greater populations at a higher standard of living. The maintenance of these greater populations depends on the fathers and mothers of the next thirty years. The problem before us is whether there will be enough people to keep things going when our grandchildren are grown up. Immigration may affect this problem considerably. Before this War, 50,000 more persons a year were entering Britain than were leaving it. In the future, Britain may attract thousands of the peasant populations of eastern Europe, and we may then be glad to let them in, just as the Dominions and the United States were before the War of 1914-18. But at present we are faced with a progressive decline of the population. The apparently satisfactory conditions at present are due, not to a good birth-rate, but to a low deathrate, resulting from improvements in public health, which allow more old people to survive. The raising 